\title{
Extraction and Characterization of Pequi Seed Oil for Biodiesel Production: A Green Management of Waste to Biofuel Using Ethanol and Heterogeneous Catalysis
}

\author{
Munique G. Guimarães, ${ }^{\oplus a}$ Rafael B. W. Evaristo, ${ }^{\circledR a}$ Julio L. de Macedo ${ }^{\circledR a, b}$ and \\ Grace F. Ghesti ${ }^{\circledR} *, a$ \\ ${ }^{a}$ Laboratório de Bioprocessos Cervejeiros e Catálise em Energias Renováveis (LaBCERva), \\ Instituto de Química, Universidade de Brasília, 70910-900 Brasília-DF, Brazil \\ ${ }^{b}$ Grupo de Novos Materiais para Catálise Química Sustentável (GNM), Instituto de Química, \\ Universidade de Brasília, 70910-900 Brasília-DF, Brazil
}

\begin{abstract}
This work reports the characterization of a vegetable oil extracted from pequi seeds, an agroindustrial residue, and its biodiesel production using ethanol and heterogeneous catalysis. The pequi seeds showed $40.73 \mathrm{wt} \%$ of extractive content, which represents a large amount of the biomass composition. The crude oil extracted from the pequi seeds with ethanol as solvent presented a high content of free fatty acids (FFAs), mainly oleic (54.14\%) and palmitic (36.71\%) acids, resulting in an acidity value of $13.8 \pm 0.1 \mathrm{mg} \mathrm{KOH} \mathrm{g}^{-1}$. The esterification/transesterification process was performed using two ion exchange resins as heterogeneous catalysts, a commercial protonic form (assigned as PR) and a zirconium-exchanged (assigned as PRZr). Conversions of 87.1 and $91.4 \%$ were achieved for PR and PRZr as catalysts, respectively, at optimal conditions (1:6 oil-to-alcohol molar ratio, $25 \mathrm{wt} . \%$ of catalyst, $100{ }^{\circ} \mathrm{C}$ and $1 \mathrm{~h}$ ). These results indicated that heterogeneous acid catalysts can be successfully applied in biodiesel production from fatty acidrich oils, such as the one extracted from pequi seeds. Also, a simultaneous process involving both oil extraction and biodiesel production was tested using PRZr as catalyst ( $25 \mathrm{wt} . \%$ of catalyst and $100^{\circ} \mathrm{C}$ ), but due to the greater amount of ethanol necessary for the oil extraction (1:16 oil to alcohol mass ratio) the conversion reached only $51.5 \%$ after $5 \mathrm{~h}$. For that reason, this work proposes a two stage system for biodiesel production that integrates oil extraction (stage one) and the esterification/ transesterification reaction (stage two) to achieve a greener process, waste-to-bioenergy.
\end{abstract}

Keywords: agroindustrial residues, pequi seeds, biodiesel, simultaneous extraction/production, heterogeneous catalysis

\section{Introduction}

The use of biomass as eco-friendly fuels can be an efficient alternative to gradually replace fossil fuels and minimize its environmental issues. ${ }^{1-3}$ Among the most utilized biofuels in the world, biodiesel has gained attention due to its origin, produced from vegetable oils or animal fats as raw materials, resulting in economic and environment benefits. ${ }^{4-6}$ The biorefinery of unexploited solid wastes from food industrial processes promotes a sustainable biomass management. ${ }^{7-10}$ For example, the use of raw cheap materials with adequate physicochemical properties for transesterification or esterification reactions could result in economically viable biodiesel processes. ${ }^{11}$

*e-mail: grace@unb.br

Editors handled this article: Teodoro S. Kaufman and Brenno A. D. Neto (Associated)
The cost of biodiesel production is highly associated to the chosen fatty material, since oil extraction (mechanical press and/or solvent) and purification (degumming, deacidification, dephosphorylation, dehydration, etc.) will determine not only the reactional system used (transesterification or esterification), but also the biofuel properties and value. Today, the most common procedure used for biodiesel production (transesterification with methanol and basic homogenous catalysis) requires expensive refine vegetable oils. ${ }^{12}$ Therefore, biofuels from non-food or biomass residues, called $2^{\text {nd }}$ and $3^{\text {rd }}$ generation biodiesel, has gathered attention in terms of process viability and environmental benefits. ${ }^{13,14}$ Integrated biodiesel systems can be used to execute both extraction and transesterification/esterification reactions in two-stages or simultaneously. These systems were already reported in small-scale processes using homogeneous catalysis and 
showed great potential for the development of biofuels with reduce costs and unit operations. ${ }^{15-17}$

Pequi (Caryocar brasiliense) is a native species from Brazilian savannah used for culinary purposes, its rich oil pulp contains nutraceutical compounds beyond its primary use. Associated with the fruit processing, to extract pulp material, a considerable amount of residues are generated since the peel and seeds have no specific purpose. Pequi seeds are normally disposed as an agroindustrial waste because of its morphological structure, which has a large number of thorns inside the seeds and it is difficult to break. ${ }^{18}$ Pequi seeds derived from agroextractivist communities could be used to produce biofuels and expand the prospect for a scenario of self-energy sustainability supply. This residue present $45-50 \%$ of oil content rich in free fatty acids (FFAs), indicating its potential for biodiesel production. According to Haas et al..$^{13}$ biodiesel can be produced from any material containing fatty acids (vegetable oils, animal fats, waste greases and waste oils) and the raw material chosen should be based on local availability, cost, government support, fuel performance, manpower and production technology.

The pequi seeds analyzed were collected in the savannah region (cerrado) located nearby Brasília (Federal District/Brazil). Pequi trees are found in different locations through the cerrado biome, for that reason the chemical composition of pequi (Caryocar brasiliense) may vary depending on the processing of the pequi, color, size, weight, almond size and pulp (like any other vegetable species that grows in different parts of the same biome). In addition, it varies by planting location, harvest, ripening point, and environmental factors. ${ }^{19}$

It is important to point out the morphological structure of pequi's fruit, since almost every work about pequi's processing deals with the characterization of oil content coming from its pulp which is the most relevant part, precisely because it is the edible part. The fruit is composed by a pericarp or exocarp that protects all the fruit, inside and connected to it there is the external mesocarp, both comprehending the fibrous part that represents about $84 \%$ of the total weight of the fruit. ${ }^{19}$ Surrounded by the external mesocarp there is the internal fruit structure also called pyrenes (botanic definition), where can be found one to four units. ${ }^{20}$ This part is composed by an internal mesocarp, where the pulp (easily recognized by its yellow color) is extracted, inside it there is the endocarp (where the thorns are concentrated) and in the central structure there is a nut (or almond). ${ }^{21}$ These structures can be seen represented in Figure 1. That way, this works deals with the oil extraction of the structure of the internal mesocarp (without the pulp), the endocarp and nut, this set was called pequi seed which is mostly thrown away as a residue from the fruit processing.

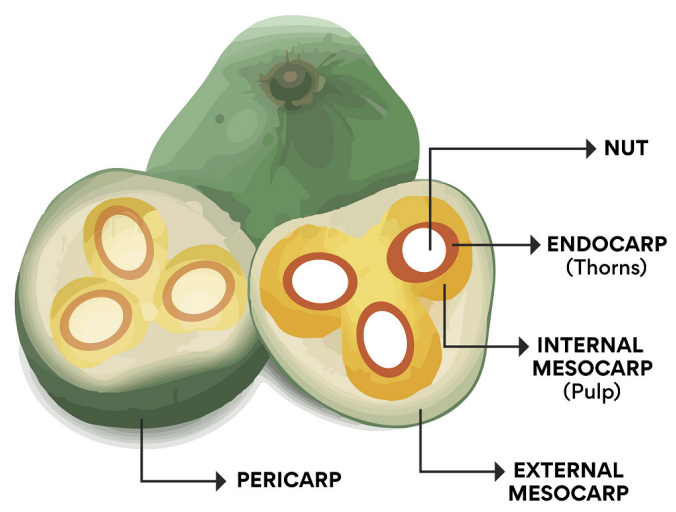

Figure 1. Morphological structure of pequi's fruit.

This work proposes the design of an integrated eco-friendly pathway for biodiesel production based on the esterification of crude oil extracted from a biomass waste (pequi seeds) with a green alcohol (ethanol) and heterogeneous catalysts. For the latter, acidic ion-exchange resins will be used due to its wide applications in catalysis, ${ }^{22-26}$ including esterification of FFAs and transesterification of triacylglycerides to produce biodiesel. ${ }^{27-31}$ The other goals of this work are: (i) the characterization of pequi seeds and its crude oil; (ii) the preparation of a heterogeneous catalysts based on a zirconium-modified resin; (iii) the studied of an integrated approach for biodiesel production using both extraction and transesterification/esterification reactions. The agroindustrial waste valorization pathway could allow an increase in resource efficiency and environmental benefits according to circular economy concept and waste-to-energy.

\section{Experimental}

\section{Materials}

Ethanol (EtOH, 99.8\%, Vetec, Duque de Caxias, RJ, Brazil), zirconium oxychloride octahydrate $\left(\mathrm{ZrOCl}_{2} \cdot 8 \mathrm{H}_{2} \mathrm{O}\right.$, 98\%, Sigma-Aldrich, Darmstadt, Germany), deuterated chloroform ( $\mathrm{CDCl}_{3}, \geq 99.8 \%$, Sigma-Aldrich, Darmstadt, Germany), $\alpha$-alumina $\left(\alpha-\mathrm{Al}_{2} \mathrm{O}_{3}, \geq 99.9 \%\right.$, Sigma-Aldrich, Darmstadt, Germany), and Dowex ${ }^{\circledR}$ 50WX8 (hydrogen form, 50-100 mesh, 50-58\% of moisture content, ion exchange capacity of $1.7 \mathrm{meq} \mathrm{mL}^{-1}$, Sigma-Aldrich, Darmstadt, Germany) were used as supplied. Pequi seeds (Empório do Cerrado, Goiânia, Brazil) were crushed in a grain mill (Arbel, São José do Rio Preto, Brazil) and classified according to ASTM D293-96. ${ }^{32}$ 
Pequi seeds characterization

Pequi seeds were oven-dry at $105^{\circ} \mathrm{C}$ for $24 \mathrm{~h}$, ground in a mill and sieved (60-100 mesh) for the followed characterization analysis and proposed experiments. The fractions (wt.\%) of moisture, ash and fixed carbon were obtained according to the Brazilian Association of Technical Standards (ABNT, NBR 8112/86). ${ }^{33}$ Soluble and insoluble lignin contents were determined according to the National Renewable Energy Laboratory (NREL, LAP/2008). ${ }^{34}$ Total extractives were quantified in ethanol:toluene $(2: 1, \mathrm{v}: \mathrm{v})$ according to TAPPI Standards \& Methods (T 204 om88). ${ }^{35}$ The holocellulose content without extractives was calculated by subtracting the full content of lignin and ash without extractives.

\section{Crude oil extraction}

For the extraction procedure, $10.0 \mathrm{~g}$ of dry pequi seeds were placed in cellulose thimbles and inserted in a Soxhlet apparatus containing $200 \mathrm{~mL}$ of ethanol. After $6 \mathrm{~h}$ of extraction, the crude oil was dried at $100{ }^{\circ} \mathrm{C}$ for $2 \mathrm{~h}$. The amount of oil (FC) extracted was determined by equation $1 .^{35}$

$\mathrm{FC}(\%)=[(\mathrm{Wp}-\mathrm{Wb}) / \mathrm{Wp}] \times 100$

where $\mathrm{Wp}$ is the oven-dry weight of pequi seeds and $\mathrm{Wb}$ is the oven-dry weight of pequi seeds after extraction.

\section{Oil characterization}

The oil acid index was executed in triplicate and based on the proceedings described by the AOCS Cd 3d-63 methodology. ${ }^{36}$ The oil composition was determined by gas chromatography-mass spectrometry (GC-MS) using a GC-17A equipment (Shimadzu, Kyoto, Japan) coupled to a mass detector, a polydimethylsiloxane column (CBPI PONAM50-042, $50 \mathrm{~m} \times 0.15 \mathrm{~mm} \times 0.42 \mu \mathrm{m})$ and the following conditions: ethanol as solvent, heating rate of $10{ }^{\circ} \mathrm{C} \mathrm{min}{ }^{-1}$ from 80 to $180{ }^{\circ} \mathrm{C}$ and the Wiley CLASS-5000 Library for identification with $95 \%$ similarity.

\section{Catalysts preparation}

The commercial ion exchange resin (Dowex $\left.{ }^{\circledR} 50 \mathrm{WX} 8\right)$ was activated with a $1 \mathrm{~mol} \mathrm{~L}^{-1} \mathrm{HCl}$ aqueous solution $\left(10 \mathrm{~g} \mathrm{~L}^{-1}\right)$ under constant stirring at room temperature for $24 \mathrm{~h}$ (assigned as PR). To prepare the zirconium-modified catalyst, the PR resin was introduced in a round-bottom flask containing a $0.1 \mathrm{~mol} \mathrm{~L}^{-1} \mathrm{ZrOCl}_{2} \cdot 8 \mathrm{H}_{2} \mathrm{O}$ aqueous solution. The suspension was kept under magnetic stirring at $80{ }^{\circ} \mathrm{C}$ for $24 \mathrm{~h}$. The obtained zirconium(IV) exchanged resin (assigned as PRZr) was washed several times with deionized water to remove chloride ions (detected by using a $0.2 \mathrm{~mol} \mathrm{~L}^{-1} \mathrm{AgNO}_{3}$ aqueous solution).

\section{Catalyst characterization}

The characterization of PR and PRZr resins was performed by the following techniques available at the Institute of Chemistry from University of Brasília. Energy dispersive X-ray fluorescence (XRF/EDX) measurements were obtained with an EDX 720HS equipment (Shimadzu, Kyoto, Japan) using a rhodium X-ray tube. $\mathrm{C}$ and $\mathrm{H}$ content were obtained with an EA 2400 Series II CHN/S equipment (PerkinElmer, Waltham, United States) using acetanilide as standard. Thermogravimetry (TG) and derivative thermogravimetry (DTG) curves were obtained with a 2960 Simultaneous DSC-TGA equipment (TA Instruments, New Castle, United States) using synthetic air (99.999\%) as purge gas $\left(10 \mathrm{~mL} \mathrm{~min}^{-1}\right)$, temperature range from 26 to $1000{ }^{\circ} \mathrm{C}\left(20^{\circ} \mathrm{C} \mathrm{min}^{-1}\right)$ and $\alpha$-alumina as reference.

\section{Catalytic activity}

Esterification/transesterification reactions were conducted using glass mini-reactors ${ }^{37}$ and the following reaction parameters were used to determine ideal conditions: catalyst amount $(10,15,20$ to $25 \mathrm{wt} . \%$, relative to pequi seeds oil), temperature $\left(80\right.$ and $\left.100{ }^{\circ} \mathrm{C}\right)$, oil to alcohol molar ratio (1:6, 1:9 and 1:15) and time (1 h).

\section{Integrated method of extraction/reaction}

The process for simultaneous oil extraction from pequi seeds and biodiesel production was designed in laboratory scale using the Soxhlet system with the main purpose to use ethanol as solvent for oil extraction and esterification/ transesterification reactions. In order to guarantee enough time and solvent volume for both extraction and reaction, the pequi seeds oil to ethanol mass ratio was $1: 16^{6}$ and the reaction time was 5 and $10 \mathrm{~h} .{ }^{6}$ The other parameters were 25 and $50 \mathrm{wt} . \%$ of catalyst amount (estimated from the oil content extracted from pequi seeds) at $100^{\circ} \mathrm{C}$.

\section{Reaction quantification}

Ester content was calculated by ${ }^{1} \mathrm{H}$ nuclear magnetic resonance (NMR) analysis using equation 2, where $\mathrm{I}_{\mathrm{TAG}+\mathrm{EE}}$ is the integration of glyceryl methylenic hydrogens and $-\mathrm{OCH}_{2}$ of ethoxy hydrogens superimposed between 4.10 
and $4.20 \mathrm{ppm} ; \mathrm{I}_{\mathrm{TAG}}$ is the integration of glyceryl methylenic hydrogens between 4.25 and $4.35 \mathrm{ppm}$; and $\mathrm{I}_{\alpha}$ is the integration of $\alpha$-acyl methylenic hydrogens in pequi seeds oil, ethyl esters and FFAs. ${ }^{38}$

$\mathrm{C}(\%)=\left[\left(\mathrm{I}_{\mathrm{TAG}+\mathrm{EE}}-\mathrm{I}_{\mathrm{TAG}}\right) / \mathrm{I}_{\mathrm{a}}\right] \times 100$

NMR measurements were conducted at $7.05 \mathrm{~T}$ in a Mercury Plus NMR spectrometer (Varian, Palo Alto, United States) using $5 \mathrm{~mm}$ Varian probes and $\mathrm{CDCl}_{3}$ as solvent. ${ }^{1} \mathrm{H}(300 \mathrm{MHz})$ spectra were obtained with pulse duration of $45^{\circ}$, a recycle delay of $1.36 \mathrm{~s}$, and 16 scans. All spectra were referenced to tetramethylsilane (TMS, $\delta=0.0 \mathrm{ppm}$ ).

\section{Results and Discussion}

\section{Characterization of pequi seeds and extracted oil}

Scapin et al. ${ }^{19}$ reported the use of a non-edible part of the pequi fruit, but different from this work, it was studied the pericarp and external mesocarp parts which was called the pequi's bark utilized as a lignocellulose matrix for chemicals production through catalytic hydrolysis (furfural and hydroxymethylfurural). Miranda $e t$ al. ${ }^{18}$ reported the use of the pequi seeds, as this work, but with different conversion route, using thermochemical process, pyrolysis and gasification, for energy production. The lignocellulosic composition and proximate analysis (moisture, fixed carbon and ash) are compared in Table 1 for both references.

Table 1. Lignocellulosic composition and proximate analysis of pequi's bark and seeds

\begin{tabular}{lcc}
\hline Component & Pequi’s bark $^{19}$ & Pequi seeds $^{18}$ \\
\hline Moisture / wt.\% & $7.00 \pm 0.2$ & $7.50 \pm 0.78$ \\
Extractives / wt.\% & $34.47 \pm 0.8$ & $40.73 \pm 0.21$ \\
Cellulose / wt.\% & $36.3 \pm 0.08$ & - \\
Hemicellulose / wt.\% & $5.35 \pm 0.06$ & - \\
Holocellulose / wt.\% & - & $22.28 \pm 0.58$ \\
Lignin / wt.\% & $25.71 \pm 0.75$ & $36.99 \pm 0.37$ \\
Fixed carbon / wt.\% & $25.27 \pm 0.8$ & $15.77 \pm 0.11$ \\
Ash / wt.\% & $2.82 \pm 0.2$ & $1.22 \pm 0.01$ \\
\hline
\end{tabular}

The chemical characterization of pequi seeds shows a high content of extractives $(40.73 \pm 0.21 \%)$. Compared to other agroindustrial residues, this value has great potential to be recovered as raw material for the production of biofuels, especially for biodiesel. In addition, a high content of lignin $(36.99 \pm 0.37 \%)$ and low content of ash $(1.22 \pm 0.01 \%)$ is beneficial for pyrolytic processes, as showed by Miranda et al. ${ }^{18}$ study, promoting one more transformation route possible for pequi seeds utilization.

An important parameter for biodiesel production is the acidity value of the oil. Vegetable oils with an acidity greater than $2 \mathrm{mg} \mathrm{KOH} \mathrm{g}^{-1}$ need to be pretreated to eliminate free fatty acids since they can neutralize basic catalysts and promote the formation of emulsions (soap formation) during the purification process. The pequi vegetable oil used in this study had an acidity value of $13.8 \pm 0.1 \mathrm{mg} \mathrm{KOH} \mathrm{g}^{-1}$. This high acidity is a consequence of partial triacyl glyceride hydrolysis and hydrolytic acidity, according to the varying degree of ripeness and the condition of the storage of the fruits. ${ }^{39}$

Industrially, when a high acidity is observed, the biodiesel formation process is carried out in two stages: (i) initial esterification of FFAs using acid catalysis and then (ii) further transesterification of triacylglycerides using an alkaline catalyst. This process acts as an alternative for correcting the acidity of low value-added raw materials, but it takes time, costs, adding more unit operations in the process and generating more waste for disposal..$^{40,41}$ Another alternative is to blend this oil with other low acidity raw materials in order to dilute the acidity until the limit value for production using basic catalysis is reached. ${ }^{8}$

Analysis of fatty acid composition is the first procedure for the preliminary assessment of the quality of crude vegetable oil and/or its transformation products. Table 2 shows the composition of pequi seeds FFAs determined by GC-MS.

Table 2. Composition of the crude oil extracted from pequi seeds using ethanol as solvent by GC-MS

\begin{tabular}{lc}
\hline & Fatty acid / wt. $\%$ \\
\hline Palmitic acid & 36.71 \\
Oleic acid & 54.14 \\
Stearic acid & 4.11 \\
Linoleic acid & 0.98 \\
Others & 4.41 \\
\hline
\end{tabular}

As shown in Table 2, palmitic $(36.71 \%)$ and oleic acid $(54.14 \%)$ were the main fatty acid constituents for the pequi seeds tested in this work, very common fatty acid for vegetable sources. Lima et al. ${ }^{21}$ analyzed pequi's pulp and nut, founding values of 35.17 and $55.87 \%$ of palmitic and oleic acid in pulp, and 43.76 and $43.59 \%$, respectively, in the nut. Also presented linoleic and stearic acid in lower concentrations, 1.53 and $2.25 \%$ in pulp; 5.51 and $2.54 \%$ in the nut, respectively. Miranda-Vilela et al. ${ }^{42}$ and Lopes et al $^{43}$ also reported the characterization of pequi's pulp founding values for palmitic and oleic acid of 41.78 and $54.28 \%$; and 40.17 and $51.59 \%$, respectively, 
confirming that the average values for palmitic and oleic acid stays between $40-50 \%$ and they are the most significantly fatty acids. Even though, the pequi seeds analyzed did not contain the pulp part it is observed that their close composition probably indicate that part of the pulp has not being extracted during processing and also could be impregnated in the thorns (presented in the endocarp).

Camargo et al. ${ }^{44}$ compiled that information reported by Miranda-Vilela et al., ${ }^{42}$ Lopes et al.$^{43}$ and Lima et al. ${ }^{21}$ presenting the major perspective of pequi cultivation to recover degraded forest areas, also showing its positive use for biofuel production. Furthermore, it presents the possibility of using not only the oil extracted from pequi's pulp like those references quoted but also by using pequi seeds oil to produce biodiesel, at this point the work only evaluates its potential due to the oil characterization with no further experiments.

Biodiesel production deals especially with the type of fatty acid ester produced since the carbon chain of the fatty acid plays an important role to maintain some physical-chemical properties. Saturated fatty acids and monounsaturated are more stable to oxidation leading to prevent degradation process. Pequi seeds showed high content of palmitic acid (a saturated fatty acid) and oleic acid (monounsaturated), forwarding good perspectives in this context. ${ }^{44,45}$

So, a fatty acid profile of the oil from pequi seeds is that affects the influence of physicochemical properties. ${ }^{17}$ For example, esters prepared with unsaturated fatty acids have low cetane number, solid waste formation and more oxidation, degradation and polymerization phenomena. ${ }^{28,46}$ In addition, they are more susceptible to hydrolysis by water contamination than other esters produced with saturated fatty acids. Because of the moisture content and acid index, acid catalysis was chosen to avoid parallel reactions, as saponification (a strategy commonly used for oils with high FFAs) ${ }^{47}$

\section{Catalysts characterization}

Composition of the $\mathrm{PR}$ and $\mathrm{PRZr}$ resins were determined by $\mathrm{CHN}$, XRF/EDX and TG/DTG analyses and are displayed in Table 3 . First, the $\mathrm{H}_{2} \mathrm{O}$ content in the materials were determined by TG/DTG, $26.69 \%$ for PR and $26.86 \%$ for PRZr.

The results showed the proportion of $3: 1$ (PR) and 3:1 (PRZr) for the ratio between $\mathrm{O}: \mathrm{S}$, about 9:1 (PR) and 11:1 (PRZr) for $\mathrm{C}: \mathrm{S}$, evidencing high density of $-\mathrm{SO}_{3} \mathrm{H}$ sites in the polymeric network for both materials (values that directly affect catalyst activity). Liu et al. ${ }^{48}$ reported the
Table 3. Elementary analysis of $P R$ and $P R Z r$

\begin{tabular}{lccccc}
\hline \multicolumn{5}{c}{ Element / $(\%, \mathrm{~m} / \mathrm{m})$} \\
\hline PR & $\mathrm{C}^{\mathrm{a}}$ & $\mathrm{H}^{\mathrm{b}}$ & $\mathrm{S}^{\mathrm{c}}$ & $\mathrm{O}^{\mathrm{d}}$ & $\mathrm{M}^{\mathrm{c}}$ \\
\hline PRZr & 54.17 & 4.60 & 16.56 & 24.79 & - \\
\hline \multicolumn{5}{c}{ Element / $(\mathrm{mol} / \mathrm{mol})$} \\
\hline PR & 44.18 & 1.44 & 10.26 & 15.35 & 28.77 \\
PRZr & $\mathrm{C}^{\mathrm{a}}$ & $\mathrm{H}^{\mathrm{b}}$ & $\mathrm{S}^{\mathrm{c}}$ & $\mathrm{O}^{\mathrm{d}}$ & $\mathrm{M}^{\mathrm{c}}$ \\
\hline
\end{tabular}

${ }^{\mathrm{a}} \mathrm{CHN}$ values; ${ }^{\mathrm{b}} \mathrm{CHN}$ values subtracted the $\mathrm{H}$ content presented in $\mathrm{H}_{2} \mathrm{O}$ molecules; 'XRF/EDX values; ${ }^{\mathrm{d}}$ calculated based on $\mathrm{S}$ content. PR: exchange resin; PRZr: exchange resin modified with Zr.

elemental analysis for the same resin studied in this work (Dowex $^{\circledR}$ 50WX8-100), using different methodologies. It was observed that proportions of $\mathrm{O}: \mathrm{S}$ and $\mathrm{C}: \mathrm{S}$ were higher 3.9:1 and 10.1:1, respectively, showing similar results considering the experimental analyses conditions. ${ }^{48}$ The density of $-\mathrm{SO}_{3} \mathrm{H}$ sites corresponds to $5.16 \mathrm{mmol} \mathrm{g}^{-1}$ for the PR and $3.20 \mathrm{mmol} \mathrm{g}^{-1}$ for PRZr, higher than catalysts already used for esterification such as HUSY zeolite $\left(0.88 \mathrm{mmol} \mathrm{g}^{-1}, \mathrm{Si} / \mathrm{Al}=5.2\right) .{ }^{49}$ The reduction of acid sites after impregnation of $\mathrm{Zr}$ species was expected since the total acid sites were calculated based on Brønsted sites and the incorporation of Lewis sites by the metal species used. ${ }^{31}$

Considering that $\left[\mathrm{Zr}_{4}(\mathrm{OH})_{8}\left(\mathrm{H}_{2} \mathrm{O}\right)_{16}\right]^{8+}$ is the most stable species in aqueous solution and how this reagent shows cluster behavior it was possible to determine that the capacity of acid sites change achieved was $91.2 \%$.

In general, it is assumed that the thermal stability of a sulfonated resin is limited to temperatures of sulfonic group losses and the thermal resistance of the polymeric material. ${ }^{50}$ Because of that, the $\mathrm{Zr}^{4+}$ species were impregnated also help to increase the thermal stability and material resistance (mainly in temperature zones between 200 and $400{ }^{\circ} \mathrm{C}$ ), confirmed through TG/DTG analysis of PR and PRZr as seen in Table S1, and comparison between Figures S1a (PR) and S1b (PRZr) in Supplementary Information section.

Effects of some reaction parameters for biodiesel productioncatalyst effect, temperature and molar ratio (alcohol:oil)

The raw material used stood out for its high content of FFAs and moisture content, resulting in high acidity index. This previous analysis prevented the use of the traditional basic catalysis process to produce biodiesel in view of the problems related to side reactions like saponification. ${ }^{51}$ Therefore, it was decided to use acid catalysis and more specific heterogeneous catalysis for transesterification/ esterification reaction connected to the scope of this 
research by valuing greener processes with the perspective of reusing the catalyst.

Aiming to optimize reaction conditions like temperature, catalyst amount and molar ratio (oil:alcohol) by using the catalyst prepared, a conventional system was used to evaluate this variables. Conventional system means the reactions take place with the oil (already extracted), alcohol and catalyst under controlled parameters.

Initial tests were performed to evaluate the effect of temperature $\left(80\right.$ and $\left.100{ }^{\circ} \mathrm{C}\right)$ with different catalysts amount (10 to $25 \%$ ) for $1 \mathrm{~h}$ reaction. This preliminary result also contributed to assess the differences between the effect of impregnating the resin catalyst with $\mathrm{Zr}$. The results can be seen in Figure 2.

As shown in Figure 2, both catalysts tested, exchange resin (PR) and impregnated with $\mathrm{Zr}(\mathrm{PRZr})$, reached conversions up to $50 \%$ with only $10 \%$ of catalyst in $1 \mathrm{~h}$ reaction $\left(80{ }^{\circ} \mathrm{C}\right)$. These preliminary results connected to the composition oil analysis, specially by its high content in FFAs, present a scenario of promising conversion values to ethyl esters in a short time reaction.

The presence of high contents of FFAs in the pequi seeds oil applied in the conditions of extraction (solventethanol, temperature and time) would possibly lead to the formation of low content of esters in an autocatalysis system. That way, the extracted material was analyzed, and it was observed a low content of esters in the final crude oil. This result would not interfere in the next reaction steps, but it is an important variable to evaluate the final conversion values in the catalytic system. As well, this parameter of conversion to esters in a non-catalytic environment was also tested to the temperature optimization with values of $15.6 \%$ at $80{ }^{\circ} \mathrm{C}$ and $21.2 \%$ at $100{ }^{\circ} \mathrm{C}$.

Analyzing Figure 2, differences in the conversion values for both temperatures tested can be observed even though the conversion is slightly different for some comparisons. The general profile reports that with the increase in temperature ( 80 to $100{ }^{\circ} \mathrm{C}$ ) both PR and PRZr increase their values of conversions. According to Feng et al..$^{52}$ as higher the temperature, higher the conversion to ethyl esters will be, due to the kinetics factors and equilibrium constant parameter. The differences in the conversion values between PR and PRZr through temperature change were most observed in 10 and $15 \%$ catalyst load, since at $80{ }^{\circ} \mathrm{C} \mathrm{PR}$ had a better performance (64.7 and $79.5 \%$, respectively) and at $100{ }^{\circ} \mathrm{C}$ this context changes with better performance for PRZr (83.7 and $88.2 \%$, respectively), this superior profile of conversion remain at 20 and $25 \%$ of catalyst amount in this temperature.

At $80{ }^{\circ} \mathrm{C}$ catalyst amount played an important role to the conversion values, $10 \%$ of PRZr achieve $53.9 \%$ conversion, contrasting with $88.6 \%$ conversion at $25 \%$ catalyst amount. For PR this profile increased from $64.7 \%$ conversion with $10 \%$ catalyst to $79.5 \%$ with $15 \%$, and in 20 and $25 \%$ this conversion slightly decreases to 77.7 and $72.9 \%$, respectively, probably demonstrating equilibrium limitations. At $100{ }^{\circ} \mathrm{C}$ the increase of conversion was less prominent, but higher than in $80{ }^{\circ} \mathrm{C}$ as discussed, PR pass from a conversion of $73.7 \%$ with $10 \%$ catalyst to $87.1 \%$ with $25 \%$, and PRZr achieve $83.7 \%$ conversion with $10 \%$ catalyst and $91.4 \%$ conversion with $25 \%$ catalyst (best result). In general, the increase in the amount of catalyst favored the conversion to ethyl esters, compatible to the increase of total active sites available in this type of catalyst. ${ }^{53}$

After the best temperature and catalyst amount conditions were determined, $25 \%$ catalyst at $100{ }^{\circ} \mathrm{C}$, the effect of the molar ratio, oil/ethanol, was analyzed for obtaining the higher conversions of oil to ethyl esters. For that, the reactions were tested in molar ratios of 1:6, 1:9 and $1: 15$.
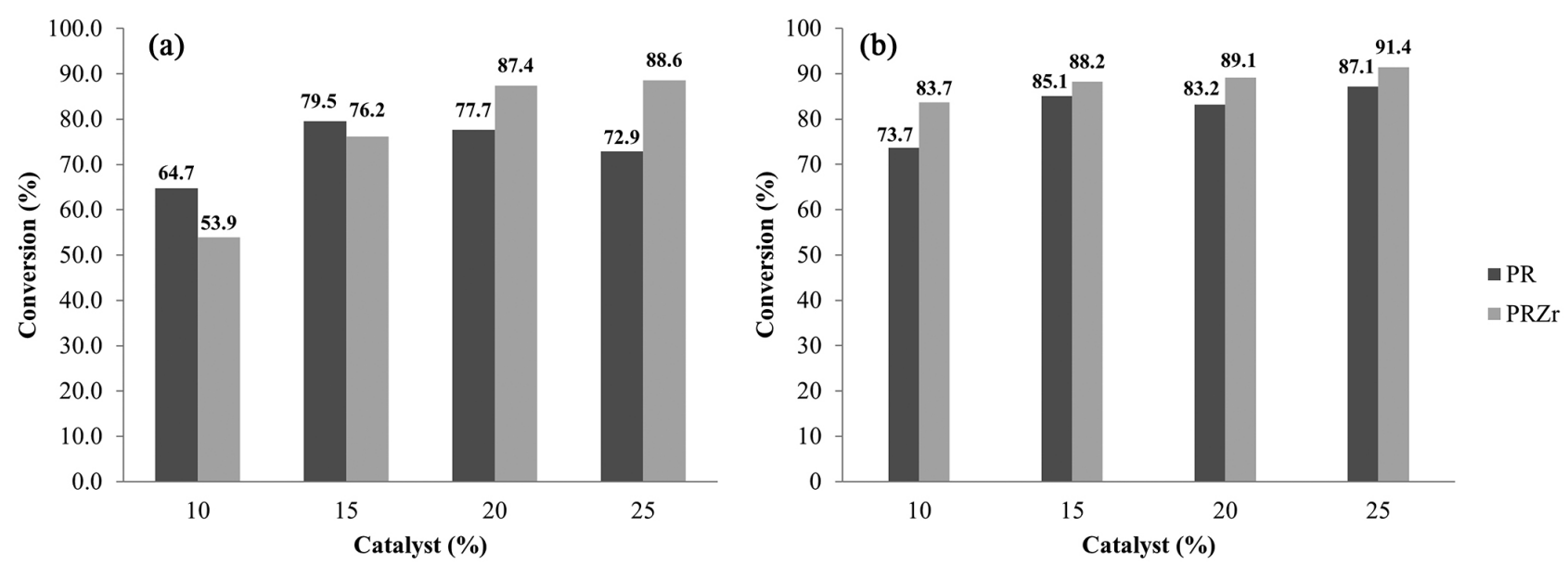

Figure 2. Conversion to esters at $80{ }^{\circ} \mathrm{C}$ (a) and $100{ }^{\circ} \mathrm{C}$ (b) with molar ratio of 1:6 (pequi seeds oil:ethanol), $1 \mathrm{~h}$ reaction and varying catalyst amount of PR and PRZr (10 to 25\%). 
The molar ratio of the reagents affects progressively the conversion in ethyl esters, as seen in Figure 3, so does the cost of biodiesel production (lower amount of alcohol less cost with raw material). The best molar ratio was of 1:6 showing $91.4 \%$ of conversion in esters. Less amount of solvent, consequently, lower contamination/poisoning of the catalyst in the esterification/transesterification reaction. ${ }^{52,54}$

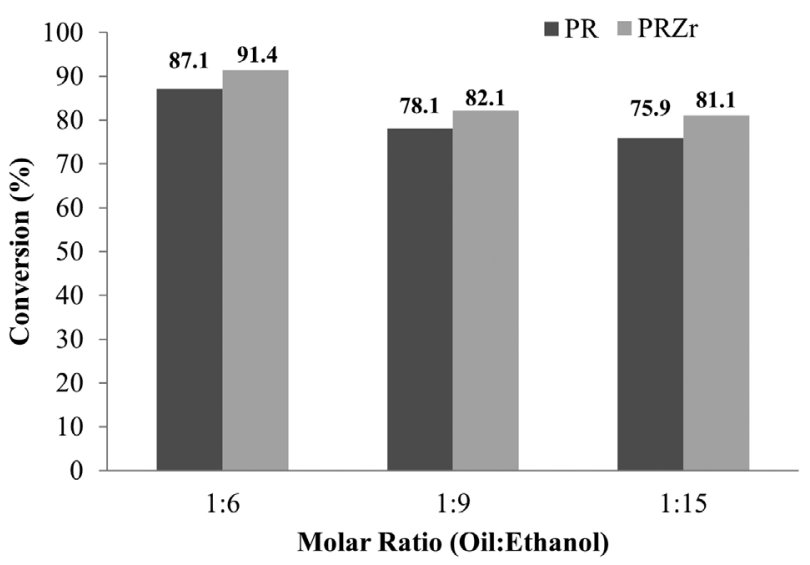

Figure 3. Conversion to esters at molar ratios of oil to ethanol of 1:6, 1:9 and $1: 15,100{ }^{\circ} \mathrm{C}$ and $25 \%$ catalyst.

Cardoso et al ${ }^{55}$ reported the use of pequi's bark, such as Scapin et al., ${ }^{19}$ to produce a carbon base acid catalyst that was applied to methyl esters production from pequi's bio-oil. In optimized conditions $99.4 \%$ conversion was achieved in $100 \mathrm{~min}$ reaction, $60{ }^{\circ} \mathrm{C}, 2.5 \mathrm{wt} . \%$ catalyst and 1:18 molar ratio (oil:methanol). Other works reported the transesterification of pequi's oil aiming to produce biodiesel,${ }^{56}$ since it is a promising feedstock, such as other vegetable oilseeds sources already used in Brazilian biofuel production. In contrast there is the fact of the utilization of an edible oil for biofuel production, that fact was overpassed by this work since it was used the pequi seeds, residue part from pulp extraction.

Pasa et al..$^{57}$ used the crude oil from macaúba palm tree (Acrocomia aculeata), a native Brazilian specie, as a vegetable oil source for ethyl esters production. High acid value (45.3 $\mathrm{mg} \mathrm{KOH} \mathrm{g}^{-1}$ ) and rich in oleic acid, the authors applied an ion-exchange resin (Amberlyst 15) as catalyst for esterification reactions. The best conversion result was $86 \%$ in a 480 min reaction with $10.5 \%$ catalyst, $80{ }^{\circ} \mathrm{C}$ and molar ratio of 1:9 (oil:ethanol). Those results showed a great use of resins to convert vegetable oils into fatty acid esters, the same proposal conducted in this work improved by a different approach to the production system discussed latter.

For comparisons between conventional homogeneous catalysis and the heterogeneous catalysts tested in this work, the optimization conditions of temperature, catalyst amount and molar ratio were performed with $\mathrm{H}_{2} \mathrm{SO}_{4}$ achieving $100 \%$ conversion to ethyl esters. This result was already expected since the mass transfer parameters are completely different between these types of catalyst, and probably lower amount of $\mathrm{H}_{2} \mathrm{SO}_{4}$ would achieve the same result.

Process for extraction of oil from pequi seeds with simultaneous biodiesel production by heterogeneous catalysis

In the conventional industrial biodiesel production, the transesterification reactions with basic homogeneous catalysis are most common to be used. The process starts with the biomass pre-treatment where the material will be milled, pressed and/or solvent extracted to separate the vegetable oil. Most oils and fats with low quality parameters need to be neutralized to decrease the content of FFAs (as well pre-esterification reaction could be performed for this purpose). The fatty content is heated and transferred to a continuous stirred tank reactor (CSTR) with the mixture of alcohol (methanol, most used) and catalyst $\left(\mathrm{CH}_{3} \mathrm{ONa}, \mathrm{NaOH}, \mathrm{KOH}\right.$, most common). After the established time for the process, the products are separated in a decanter tank where mostly glycerin, alcohol and catalyst will be removed from the biodiesel (some industrial plants also could transfer the biodiesel to another reactor and reload it with catalyst and alcohol to increase conversion performance). The conversion of oil/fat to esters must attend the regulation specification of each country. Especially in Brazil, biodiesel must contain 96.5\% of esters according to Brazilian National Agency for Petroleum, Natural Gas and Biofuels (ANP).$^{58}$ In a typical system with base homogeneous catalysis biodiesel also has to pass through a purification process mostly proceed with water cleaning several times for withdrawal of the remaining impurities like residual soap and catalyst. This step is followed by drying process to retain traces of water. The conventional biodiesel production system is outlined in Figure 4.

Regarding the acid homogeneous process, the system can be interpreted in the same diagram, since the pretreatment of the oil will not be essential and the post cleaning process, after the decanter tank, will not be necessarily this rigorous like for base catalysis. This system can now be properly compared to the heterogeneous catalysis one.

Aiming to propose a more sustainable and ecological biodiesel production system and mostly designing a process connected to the specification of the biomass used in 


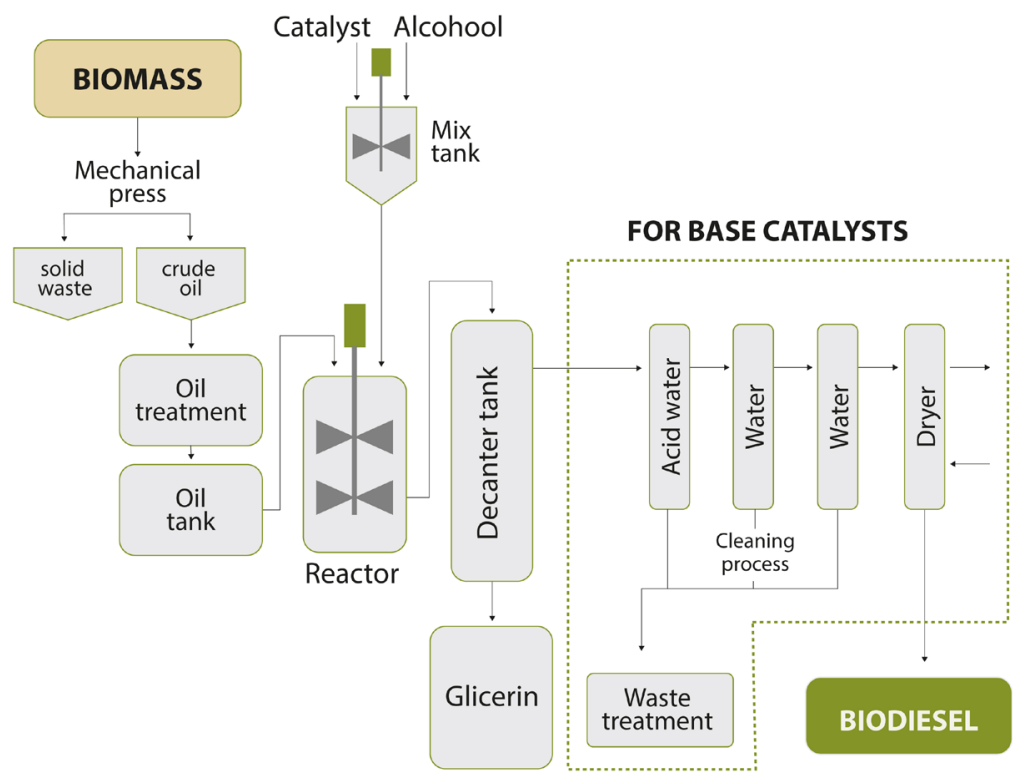

Figure 4. Diagram of the conventional process for biodiesel production.

this work (waste biomass from a residual crop with high contents of oil and FFAs), in Figure 5 is presented the system applied for this objective. The process refers to the simultaneous extraction and production of biodiesel from pequi seeds by means of heterogeneous catalysis in a single step process to obtain fatty acid esters (biodiesel). In the displayed system, pequi seeds (milled in appropriate granulometry) are added together with ethanol which will extract the oil fraction. The mixture of extracted oil and ethanol will be sent to the reaction tank where the solid catalyst is (resins in this context). The reaction will take place in the optimized conditions of temperature/time. The product then goes to the decanter tank for separation of glycerin and ethanol, this one will be sent to the distillation

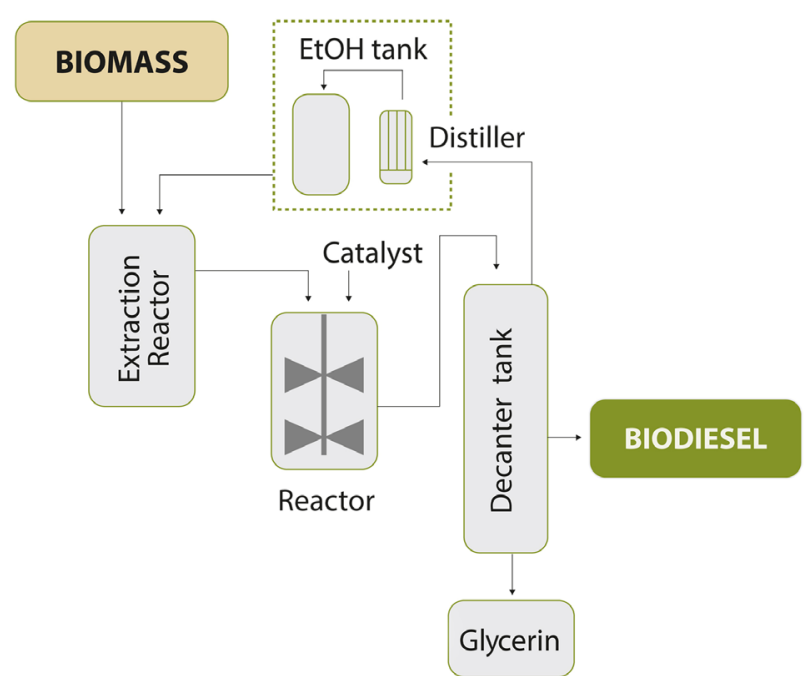

Figure 5. Proposed process diagram for production of biodiesel by simultaneous extraction and reaction by heterogeneous catalysis with ethanol as extractant and reactant. tower to return to the extraction reactor as a feedback current (solvent reuse).

Necessarily for this process molar ratio between alcohol and oil will have to be adjusted, since there must be enough amount of alcohol for both roles (extraction and reagent of esterification/transesterification reaction). The solvent recovery is also used in the conventional process (logically with more purification steps needed), but this system in particular plays two important roles decreasing unit operations and consequently production costs.

Resuming the main differences, also advantages, between the two systems presented are less reactors in the simultaneous extraction/production process, no need of extracting/pre-treating the oil from the raw material previously, reusing of the solvent that will play two roles in the process (extraction and reagent) and also the capacity of reusing the heterogeneous catalyst (one of the most important and significant possibilities for this type of catalyst) promoting the environmental friendly focus of the proposed system. ${ }^{59}$

Figure 6 presents the results of the reactions using the proposed system in Figure 5. As it was explained, the ratio between ethanol and pequi's oil had to be adjusted to this new system, that way a mass ratio of 1 to 16.6 of pequi seeds and ethanol, respectively, was used (the ratio was estimated by the minimum volume of ethanol necessary to be recovered and still have enough to continues both reaction steps at the same time). By using the best conditions of catalyst amount and temperature from the optimization parameters section, $25 \%$ of the catalyst $\mathrm{PRZr}$ was used at $100{ }^{\circ} \mathrm{C}$. With $5 \mathrm{~h}$ process the conversion achieved $51.5 \%$ and with $10 \mathrm{~h}$ process there were not much difference, $55.1 \%$ conversion. At this point, 
the reuse of the $10 \mathrm{~h}$ catalyst was also conducted, decreasing the conversion to $19.7 \%$.

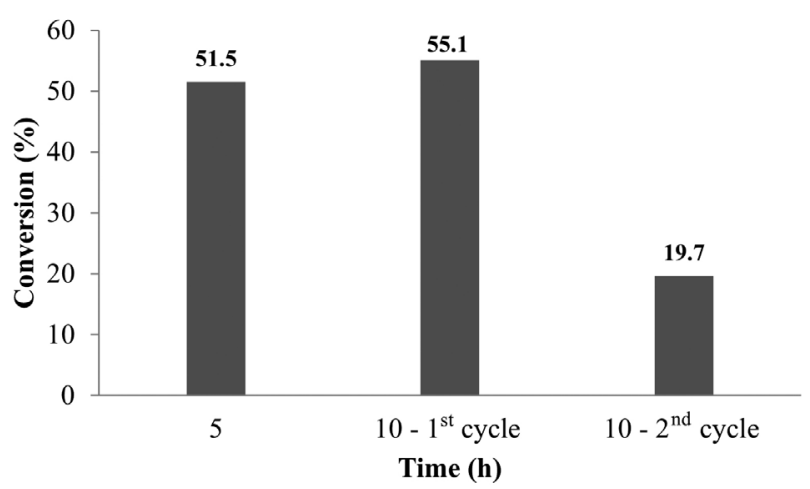

Figure 6. Conversion to esters using simultaneous extraction and production of biodiesel using $25 \% \mathrm{PRZr}, 1: 16.6(\% \mathrm{~m} / \mathrm{m}$ pequi seeds:ethanol), $100{ }^{\circ} \mathrm{C}$, testing $5 \mathrm{~h}$ process, $10 \mathrm{~h}$ and a $2^{\text {nd }}$ cycle of $10 \mathrm{~h}$ with the same catalyst load (reuse).

In esterification and transesterification reactions, the use of higher quantities of alcohol compared to the oil content aims to force the reaction equilibrium to balance in favor of the ester formation. However, the excessive level of alcohol, ethanol in this case, used in the proposed method deactivate the catalyst, mostly by blocking the catalyst surface to the substrate access to the active sites, consequently a reduction in catalytic activity throughout the esterification/transesterification reaction was observed and thus decreased conversion to esters when compared to the conventional method..$^{38}$

Although, the simultaneous extraction and production of biodiesel with heterogeneous catalyst achieved lower performance than what was tested in the optimization experiments, the system showed to have minimum conditions to operate for its objective, building a more sustainable biodiesel process. Some catalysts are reported in the literature, ${ }^{16,17,54,60,61}$ basic and acid, in which they are used to the production of biodiesel in a single reaction system (also called one-step process), where the extraction of raw materials containing high levels of FFAs occurs together with the esterification/transesterification reaction. There are some limitations, but they are great examples of simultaneous process for comparative studies.

Georgogianni et al. ${ }^{54}$ reported in situ transesterification of cottonseeds with methanol and ethanol. The seeds were milled and mixed with the alcohol and $\mathrm{NaOH}$ (catalyst) all in the same reaction flask. In best reaction conditions, for methanol $\left(60^{\circ} \mathrm{C}, 2 \% \mathrm{NaOH}\right)$, in ultrasonic and mechanical stirring, it was achieved $95 \%$ yields to methyl esters after 20 min. In ethanol $\left(80{ }^{\circ} \mathrm{C}, 2 \% \mathrm{NaOH}\right)$ with ultrasonic stirring the reaction achieved $98 \%$ yield in 40 min and with mechanical stirring $78 \%$ yield after $4 \mathrm{~h}$.
Pradhan et $a l .{ }^{60}$ reported a similar method for in situ transesterification process with basic catalysis, entitled reactive extraction. Castor seeds were macerated and transferred to a flask (connected to a reflux condenser) where was added a $\mathrm{KOH}-m e t h a n o l$ solution, also hexane $(15 \% \mathrm{v} / \mathrm{v})$ was added as a co-solvent to improve fatty extraction. In optimum conditions (molar ratio of methanol to oil, $225: 1,1.0 \mathrm{wt} . \%$ catalyst, $350 \mathrm{rpm}$ at $55^{\circ} \mathrm{C}$ ), it was achieved $88.2 \%$ ester yield.

The use of a co-solvent is very common in simultaneous extraction of fatty content and production of esters from different biomass. In conventional process, commonly the use of a solvent precedes the transesterification reaction since the oil has to be extracted and then will be followed by the reaction procedure.

Shuit et al. ${ }^{16}$ use a co-solvent for reactive extraction of Jatropha curcas L. seeds and transesterification to biodiesel production, but different from Georgianni et al. ${ }^{54}$ and Pradhan et al., ${ }^{60}$ it is used acid catalysis. In a round bottom flask, the seeds were loaded with methanol, $\mathrm{H}_{2} \mathrm{SO}_{4}$ and $n$-hexane (co-solvent). In a reaction temperature of $60{ }^{\circ} \mathrm{C}, 24 \mathrm{~h}$ reaction, methanol to seed ratio of $7.5 \mathrm{~mL} \mathrm{~g}^{-1}$ and 15 wt. $\%$ of $\mathrm{H}_{2} \mathrm{SO}_{4}$, the oil extraction efficiency and fatty acid methyl esters yield reached 91.2 and $99.8 \%$, respectively. Özgül-Yücel and Türkay ${ }^{62}$ also reported the use of $\mathrm{H}_{2} \mathrm{SO}_{4}$ for biodiesel production from rice bran. It was studied the influence of different FFAs content to methyl ester formation in situ transesterification. In optimized conditions, the experiments resulted in methyl ester content higher than $80 \%$.

Other type of system already reported is the use of Soxhlet extractor since it is possible to recover the solvent/alcohol at the same time the mixture with fatty content can return to the reaction flask where the catalyst is loaded. Li et al. ${ }^{61}$ reported the use of this kind of system with the production of biodiesel from microalgae (Nannochloropsis sp.) and a solid base $\mathrm{Mg}-\mathrm{Zr}$ catalyst. The highest methyl ester yield was $28 \%$ using methanol and methylene dichloride $(3: 1, \mathrm{v} / \mathrm{v})$, reaction temperature of $65^{\circ} \mathrm{C}, 10 \%$ catalyst and $4 \mathrm{~h}$ reaction. Zhang et al..$^{17}$ also used a Soxhlet extractor, in this case testing Zanthoxylum bungeanum seeds, which has acid index higher than $40 \mathrm{mg} \mathrm{KOH} \mathrm{g}^{-1}$ (much higher than the biomass used in this work). Solvent-to-seed ratio was evaluated, as well as reaction time, different solvents and alcohols (methanol and ethanol). Over optimization experiments both homogeneous $\left(\mathrm{H}_{2} \mathrm{SO}_{4}\right.$ and $\left.\mathrm{NaHSO}_{4}\right)$ and heterogeneous acid catalysts $\left(\mathrm{SnCl}_{4}\right.$ and $\left.\mathrm{Fe}_{2}\left(\mathrm{SO}_{4}\right)_{3}\right)$ were tested. The tests resulted in the use of $\mathrm{H}_{2} \mathrm{SO}_{4}$ in Soxhlet system, $95^{\circ} \mathrm{C}$, and $12 \mathrm{~h}$ reaction achieving $94 \%$ conversion to methyl esters (conversion to ethyl esters was not calculated since there were experiment analysis limitations). 
Different from the systems already mentioned, this work using pequi seeds intended to use no co-solvent for extraction purposes, so that use only the alcohol with both roles as extractant and reagent. Also, it was given priority to use only ethanol since its origin come from a renewable source (in Brazil mainly produced from sugar cane), connecting to the scope of this research that propose an entire greener system for biodiesel production. Mostly of the studies indicated ${ }^{16,17,61}$ compare in situ/one-setp systems to produce biodiesel with the conventional one (first extracting the oil content and then performing transesterification reaction), as well as it was realized in this work. This type of comparison indicates that even though the simultaneous process does not get to high maximum values of conversion, through optimization and further adjustments they could possibly get close to the results expected (high efficiency process).

\section{Catalyst reuse and leaching studies}

Catalyst reuse were performed to evaluate the effectiveness of the PRZr in more than one cycle reaction, as well as evaluate the potential leaching of $\mathrm{Zr}$ species impregnated in the exchange resin in the simultaneous extraction and production system. These tests were conducted with $50 \%$ catalyst, $6 \mathrm{~h}$ reaction and 1:16 mass ratio of pequi seeds and ethanol, since the conversion for $25 \%$ catalyst presented median conversion rates, even for a long period of time $(10 \mathrm{~h})$. To better study the interaction of the catalyst in the reaction it was decided to stress those conditions. In Figure 7, the conversions to ethyl esters are presented for the first, second and third recycle of the catalyst; it is important to point out that no washing or treatment were used with the catalyst for the reuse tests. Also, it was tested a $24 \mathrm{~h}$ process, in these same conditions, achieving a maximum of $82.2 \%$ conversion, $20 \%$ higher than the first cycle tested.

The conversion to ethyl esters decreased with the additional recycles, starting with $62.9 \%$ conversion in the first cycle and here achieving a value of $20 \%$ conversion in the third cycle. Without posterior treatment applied to the catalyst during the tests, possibly the active sites of the resin were covered by agglomeration of organic and aqueous residues coming from the previous reaction, justifying the reduction of the conversion. For comparative analysis in this system, $24 \mathrm{~h}$ reaction was tested in the same condition.

$\mathrm{XRF} / \mathrm{EDX}$ analysis of the ethyl ester obtained after each cycle found no trace of $\mathrm{Zr}$ species, which confirms that the catalyst deactivation was not by the leaching of inorganic species but possibly due to the accelerated polymeric chain degradation. This was confirmed by TG/DTG analysis,

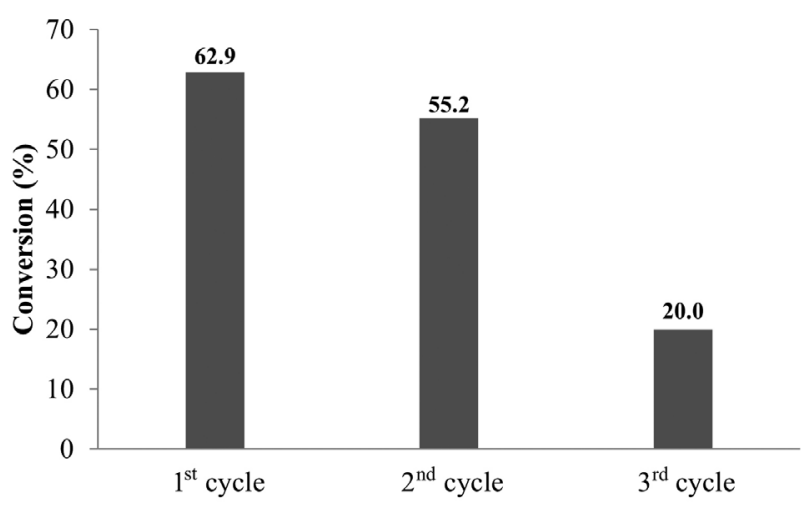

Figure 7. Conversion to esters using simultaneous extraction and production of biodiesel using 50\% PRZr, 1:16 (\% m/m pequi seeds:ethanol), $100{ }^{\circ} \mathrm{C}$ and $6 \mathrm{~h}$ process.

seen in Table 4, where a huge difference in the first zone degradation temperature can be observed for the PRZr of the first cycle to the third cycle. A massive loss between 200 and $400{ }^{\circ} \mathrm{C}$ for PRZr $3^{\text {rd }}$ cycle confirmed that the structure of the resin collapse and loss its organized tridimensional structure (an organized structure contributes to thermal stability).

Table 4. Mass losses by TG analysis for PRZr and PRZr $3^{\text {rd }}$ cycle

\begin{tabular}{lcc}
\hline Temperature \\
degradation zone $/{ }^{\circ} \mathrm{C}$ & \multicolumn{2}{c}{ Mass loss / \% } \\
\cline { 2 - 3 } & PRZr $1^{\text {st }}$ cycle & PRZr 3 ${ }^{\text {rd }}$ cycle \\
\hline $200-400$ & 9.4 & 46.0 \\
$400-800$ & 74.9 & 42.6 \\
$800-1000$ & 15.71 & 11.7 \\
\hline
\end{tabular}

PRZr: exchange resin modified with Zr.

Based on the foregoing, the greatest advantages of the utilization of this reactor in the extraction of vegetable oil with simultaneous production of fatty acid esters (biodiesel) is that, despite the alcohol, oilseeds or catalyst used, the number of unit operations needed is reduced, there is the possibility of recycling the solvent, use of raw material originated from agroindustrial oil residues, separation of the catalyst at the end of the process to reusing, reduction of the washing steps of the final product and the simultaneous occurrence of esterification and transesterification reactions, which decreases substantially production costs. The adaptations made to the conventional system provided the construction of an environmental and eco-friendly process connected to the green chemistry principles largely discussed for the conventional industrial systems.

The development of alternative methods for biodiesel production can be found in a large variety of papers discussing not only operational systems, like reactors design and biomass processing, but also reaction types and conditions, like non-catalyst systems with super 
critical solvent for hydrolysis/esterification of oils. ${ }^{63,64}$ Patents play an important role in this context because it is the concrete formulation of a technological new product. However, both articles and patents share the same scenario, processes that are in majority described for laboratory scale. So, it is necessary the investment in research to scale-up the biodiesel production, since it adds some benefits to this sector, from the biomass raw material to the process/production and distribution. Therefore, if the proposed method for simultaneous extraction and production of biodiesel in this article could be classified by the Technology Readiness Level (TRL), that sates the level of technological maturity of a system/product, it would be classified between 3-4, as quoted by Quintella. ${ }^{65}$ This classification shows that some important steps in the development of this technology need to be improved for scale-up to have the possibility to get transferred from the lab scale to a commercialized market product.

However, the proposed technology shows potential for industrial application, since the equipment and materials for its execution are already used in great-sized industries, although with another technologic purpose, which corroborates in the applicability and cost reduction for its implementation.

\section{Conclusions}

The perceptive conclusions of this paper could support in recommending optimum paths to more economically valorization of low-cost feedstock through transesterification/esterification valorization route, encouraging waste-to-energy development and circular economy principles. Due to the high moisture and extractable content present in the seeds, in addition to the high acid index, the route of heterogeneous acid catalysis in the simultaneous transesterification and esterification reactions was chosen.

These results indicated that heterogeneous acid catalysts can be successfully applied in biodiesel production from fatty acid-rich oils, such as the one extracted from pequi seeds. Also, the proposed route to treat the solid waste from pequi's industry, a two stage system for biodiesel production can integrate oil extraction (stage one) and the esterification/transesterification reaction (stage two) was tested using PRZr as catalyst (25 wt.\% of catalyst and $100{ }^{\circ} \mathrm{C}$ ), but due to the greater amount of ethanol necessary for the oil extraction (1:16 oil to alcohol molar ratio) the conversion reached only $51.5 \%$ after $5 \mathrm{~h}$.

This system proposes a combination of two strategies for greener biodiesel production, which is the oil extraction step and the use of heterogeneous catalysis. The experiments performed confirm that this system needs to be optimized to achieve best alcohol to oil ratio and a better catalyst performance. That way, other catalysts (carbonaceous and Lewis acids materials) could also be tested achieving better conversions showing higher activities.

So, it is possible to produce fatty acid esters in different design systems, decreasing the number of unit operations, respecting green-chemistry principles, reducing production costs coming closer towards zero waste concept.

\section{Supplementary Information}

Supplementary information is available free of charge at http://jbcs.sbq.org.br as PDF file.

\section{Acknowledgments}

This study was financed by the Coordination of Superior Level Staff Improvement-Brazil (CAPES) - Finance Code 001, through the master scholarship granted to Ms Munique Guimarães. The authors would also like to thank the support of National Council for Scientific and Technological Development (CNPq), Federal District Research Support Foundation (FAPDF) and the Institute of Chemistry of the University of Brasília (IQ/UnB).

\section{Author Contributions}

Munique G. Guimarães was responsible for formal analysis, investigation, methodology, writing original draft, writing review and editing; Rafael B. W. Evaristo for formal analysis, investigation, writing original draft, review and editing; Julio L. de Macedo for conceptualization, funding acquisition, investigation, writing original draft; Grace F. Ghesti for conceptualization, funding acquisition, investigation, project administration, writing review and editing.

\section{References}

1. Malico, I. C.; Pereira, R. N.; Gonçalves, A. C.; Sousa, A. M. O.; Renewable Sustainable Energy Rev. 2019, 112, 960.

2. Banković-Ilić, I. B.; Stojković, I. J.; Stamenković, O. S.; Veljkovic, V. B.; Hung, Y. T.; Renewable Sustainable Energy Rev. 2014, 32, 238.

3. Chopra, J.; Dineshkumar, R.; Bhaumik, M.; Dhanarajan, G.; Kumar, R.; Sen, R.; RSC Adv. 2016, 6, 70364.

4. Asri, N. P.; Machmudah, S.; Budikarjono, K.; Roesyadi, A.; Goto, M.; Chem. Eng. Process. Process Intensification 2013, 72,63 .

5. Daud, N. M.; Abdullah, S. R. S.; Hasan, H. A.; Yaakob, Z.; Process Saf. Environ. Prot. 2015, 94, 487. 
6. Popp, J.; Harangi-Rákos, M.; Gabnai, Z.; Balogh, P.; Antal, G.; Bai, A.; Molecules 2016, 21, 285.

7. Jedliński, M.; Procedia-Social Behavioral Sci. 2014, 151, 102.

8. Seroka-Stolka, O.; Procedia-Soc. Behav. Sci. 2014, 151, 302 .

9. Agrawal, S.; Singh, R. K.; Murtaza, Q.; Resour., Conserv. Recycl. 2015, 97, 76.

10. Zabaniotou, A.; Kamaterou, P.; Pavlou, A.; Panayiotou, C.; J. Cleaner Prod. 2018, 172, 3387.

11. César, A. S.; Werderits, D. E.; Saraiva, G. L. O.; Guabiroba, R. C. S.; Renewable Sustainable Energy Rev. 2017, 72, 246.

12. Kartika, I. A.; Yani, M.; Ariono, D.; Evon, P.; Rigal, L.; Fuel 2013, 106, 111

13. Haas, M. J.; McAloon, A. J.; Yee, W. C.; Foglia, T. A.; Bioresour. Technol. 2006, 97, 671.

14. Dabdoub, M. J.; Bronzel, J. L.; Rampin, M. A.; Quim. Nova 2009, 32, 776.

15. Rahimi, A.; Moradi, G.; Abolhasan, A. S.; Ardjmand, M.; Environ. Prog. Sustainable Energy 2018, 37, 518.

16. Shuit, S. H.; Lee, K. T.; Kamaruddin, A. H.; Yusup, S.; Fuel 2010, 89,527 .

17. Zhang, L.; Wu, H. T.; Yang, F. X.; Zhang, J. H.; Fuel Process. Technol. 2015, 131, 452.

18. Miranda, M. R. S.; Veras, C. A. G.; Ghesti, G. F.; J. Waste Manage. 2020, 103, 177.

19. Scapin, E.; Rambo, M. K. D.; Viana, G. C. C.; Borges, M. S.; Rambo, M. C. D.; Carneiro, C.; J. Braz. Chem. Soc. 2020, 31, 1383.

20. Moura, N. F.; Chaves, L. J.; Naves, R. V.; Rev. Arvore 2013, 37, 905.

21. Lima, A. D.; Silva, A. M. D. O.; Trindade, R. A.; Torres, R. P.; Mancini-Filho, J.; Rev. Bras. Frutic. 2007, 29, 695.

22. Abduaziz, O.; Cheng, J. K.; Tahar, R. M.; Varma, R.; Procedia Eng. 2015, 100, 960.

23. Mansir, N.; Taufiq-Yap, Y. H.; Rashid, U.; Lokman, I. M.; Energy Convers. Manage. 2017, 141, 171.

24. Mardhiah, H. H.; Ong, H. C.; Masjuki, H. H.; Lim, S.; Lee, H. V.; Renewable Sustainable Energy Rev. 2017, 67, 1225.

25. Mitsutani, A.; Catal. Today 2002, 73, 57.

26. Raia, R. Z.; da Silva, L. S.; Marcucci, S. M. P.; Arroyo, P. A.; Catal. Today 2017, 289, 105.

27. Cordeiro, C. S.; Silva, F. R. D.; Wypych, F.; Ramos, L. P.; Quim. Nova 2011, 34, 477.

28. Hartono, R.; Mulia, B.; Sahlan, M.; Utami, T. S.; Wijanarko, A.; Hermansyah, H.; AIP Conf. Proc. 2017, 1826, 020020.

29. He, B.; Shao, Y.; Ren, Y.; Li, J.; Cheng, Y.; Fuel Process. Technol. 2015, 130, 1.

30. Ma, Y.; Wang, Q.; Sun, X.; Wu, C.; Gao, Z.; Renewable Energy 2017, 107, 522 .

31. Turhanen, P. A.; Leppänen, J.; Vepsäläinen, J. J.; ACS Omega 2019, 4, 8974.
32. ASTM D293-96: Standard Test Method for Sieve Analysis of Coke, ASTM International, West Conshohocken, PA, 2010.

33. ABNT NBR 8112:1986: Carvão Vegetal - Análise Imediata Método de Ensaio, ABNT: Rio de Janeiro, 1986.

34. Sluiter, A.; Hames, B.; Ruiz, R.; Scarlata, C.; Sluiter, J.; Templeton, D.; Crocker, D.; Determination of Structural Carbohydrates and Lignin in Biomass; National Renewable Energy Laboratory: Denver West Parkway Golden, Colorado, 2008, available at https://www.nrel.gov/docs/gen/fy13/42618. pdf, accessed in October 2021.

35. Technical Association of the Pulp and Paper Industry (TAPPI); T-264 om-88: Preparation of Wood for Chemical Analysis, TAPPI: Atlanta, GA, 1996.

36. Firestone, D.; Official Method Cd 3d-63, Acid Value; Official Methods and Recommended Practices of the American Oil Chemists' Society: Urbana, IL, USA, 1973.

37. Ghesti, G. F.; Macedo, J. L.; Parente, V. C. I.; Dias, J. A.; Dias, S. C. L.; Appl. Catal., A 2009, 355, 139.

38. Ghesti, G. F.; Macedo, J. L.; Resck, I. S.; Dias, J. A.; Dias, S. C. L.; Energy Fuels 2007, 21, 2475.

39. Santos, F. S.; Santos, R. F.; Dias, P. P.; Zanão Jr., L. A.; Tomassoni, F.; Acta Iguazu 2013, 2, 46, available at https://erevista.unioeste.br/index.php/actaiguazu/article/view/8620, accessed in October 2021.

40. Cavalcante, K. S. B.; Penha, M. N. C.; Mendonça, K. K. M.; Louzeiro, H. C.; Vasconcelos, A. C. S.; Maciel, A. P.; Souza, A. G.; Silva, F. C.; Fuel 2010, 89, 1172.

41. Zabeti, M.; Daud, W. M. A. W.; Aroua, M. K.; Fuel Process. Technol. 2009, 90, 770.

42. Miranda-Vilela, A. L.; Grisolia, C. K.; Resck, I. S.; Mendonça, M. A.; Quim. Nova 2009, 32, 2310.

43. Lopes, R. M.; Silva, J. P.; Vieira, R. F.; Silva, D. B.; Gomes, I. S.; Agostini-Costa, T. S.; Rev. Bras. Frutic. 2012, 34, 635.

44. Camargo, M. P.; Estevam, A.; Feroldi, M.; Cremonez, P. A.; J. Agric. Sci. 2014, 3, 180.

45. Ribeiro, M. C.; Vilas Boas, E. V. B.; Riul, T. R.; Pantoja, L.; Marinho, H. A.; Santos, A. S.; Food Sci. Technol. 2012, 32, 386.

46. Jacobson, K.; Gopinath, R.; Meher, L. C.; Dalai, A. K.; Appl. Catal., B 2008, 85, 86.

47. Suarez, P. A.; Santos, A. L.; Rodrigues, J. P.; Alves, M. B.; Quim. Nova 2009, 32, 768.

48. Liu, C. H.; Chen, B. H.; Hsueh, C. L.; Ku, J. R.; Jeng, M. S.; Tsau, F.; Int. J. Hydrogen Energy 2009, 34, 2153.

49. Borges, L. D.; Moura, N. N.; Costa, A. A.; Braga, P. R. S.; Dias, J. A.; Dias, S. C. L.; Macedo, J. L.; Ghesti, G. F.; Appl. Catal., A 2013, 450, 114.

50. Siril, P. F.; Cross, H. E.; Brown, D. R.; J. Mol. Catal. A: Chem. 2008, $279,63$.

51. Marchetti, J. M.; Errazu, A. F.; Fuel 2008, 87, 3477.

52. Feng, Y.; He, B.; Cao, Y.; Li, J.; Liu, M.; Yan, F.; Liang, X.; Bioresour. Technol. 2010, 101, 1518. 
53. Yadav, G. D.; Thathagar, M. B.; React. Funct. Polym. 2002, 52, 99.

54. Georgogianni, K. G.; Kontominas, M. G.; Pomonis, P. J.; Avlonitis, D.; Gergis, V.; Fuels 2008, 22, 2110.

55. Cardoso, C. M. M.; Zavarize, D. G.; Vieira, G. E. G.; Ind. Crops Prod. 2019, 139, 111485.

56. Silva, T. A.; Assunção, R. M. N.; Vieira, A. T.; Oliveira, M. F.; Batista, A. C. F.; Fuel 2014, 136, 10.

57. Pasa, T. L. B.; Souza, G. K.; Diório, A.; Arroyo, P. A.; Pereira, N. C.; Renewable Energy 2019, 146, 469.

58. Agência Nacional do Petróleo, Gás Natural e Biocombustíveis (ANP); Especificação do Biodiesel; available at https://www. gov.br/anp/pt-br/assuntos/producao-e-fornecimento-debiocombustiveis/biodiesel/especificacao-do-biodiesel, accessed in November 2021.
59. Guimaraes, M. G.; Evaristo, R. B. W.; Lima, L. A.; Fernandes, T. L.; Macedo, J. L.; Costa, A. A.; Braga, P. R. S.; Ghesti, G. F.; Cad. Prospecção 2017, 10, DOI:10.9771/cp.v10i4.23014.

60. Pradhan, S.; Madankar, C. S.; Mohanty, P.; Naik, S. N.; Fuel 2012, 97, 848 .

61. Li, Y.; Lian, S.; Tong, D.; Song, R.; Yang, W.; Fan, Y.; Qing, R.; $\mathrm{Hu}, \mathrm{C} . ;$ Energy 2011, 88, 3313.

62. Özgül-Yücel, S.; Türkay, S.; J. Am. Oil Chem. Soc. 2002, 79, 611.

63. Minami, E.; Saka, S.; Fuel 2006, 85, 2479.

64. Mello, B. T. F.; Gonçalves, J. E.; Rodrigues, G. M.; Cardozo-Filho, L.; Silva, C.; Ind. Crops Prod. 2017, 97, 110.

65. Quintella, C. M.; Cad. Prospecção 2017, 10, DOI: 10.9771/ cp.v10i1.21864. 